\title{
Incidence of Stroke in Young Adults: A Review
}

\author{
Carmine Marini, ${ }^{1}$ Tommasina Russo, ${ }^{1}$ and Giorgio Felzani ${ }^{2}$ \\ ${ }^{1}$ Dipartimento di Medicina Interna e Sanità Pubblica, Università degli Studi L'Aquila Coppito, 67010 L'Aquila, Italy \\ ${ }^{2}$ Casa di Cura San Raffaele, 67039 Sulmona, Italy
}

Correspondence should be addressed to Carmine Marini, marini@cc.univaq.it

Received 15 September 2010; Accepted 18 November 2010

Academic Editor: Turgut Tatlisumak

Copyright (C) 2011 Carmine Marini et al. This is an open access article distributed under the Creative Commons Attribution License, which permits unrestricted use, distribution, and reproduction in any medium, provided the original work is properly cited.

Introduction. Stroke in the young may have a dramatic impact on the quality of life in survivors. This study was aimed to evaluate incidence of first-ever stroke in the young by means of a systematic review. Materials and Methods. All papers on incidence of stroke in the young published after 1980, were identified by electronic search of Medline and manual search of reference lists. Only studies recruiting subjects under 44 years of age and with a lower age limit not higher than 20 years were included. Incidence rates were standardized to the 2000 European population according to the direct method. Poisson regression analysis was used to compare studies. Results. 29 studies including 3548 participants were identified. Incidence rates, after excluding a few outliers, ranged between 8.63 and 19.12 for crude rates and between 8.70 and 21.02 for standardized rates. Heterogeneity among studies was statistically significant but improved after excluding 4 studies. Few studies reported the proportions of stroke subtypes. Conclusions. Stroke in subjects under 45 years of age is not such a rare disease and requires specific preventive programs.

\section{Introduction}

According to available data, fewer than $5 \%$ of all strokes occur in subjects under 45 years of age, in Western countries [1]. Higher proportions, between 19 and 30\%, were reported in developing countries [2, 3]. Stroke incidence studies in the young were reported in several surveys and a few community-based studies that used different methodology and results were often very different [1, 3-30]. Moreover, in many studies, reported incidence rates had wide confidence intervals because of the small number of incident cases in the young [1,3-30].

This study was aimed to evaluate incidence of first-ever stroke in the young by means of a systematic review of the literature.

\section{Materials and Methods}

In the present review, data were identified by searches of Medline and from the references of relevant articles published after 1980. Different subsets of studies were potentially eligible for different parts of this review. The search terms "population-based," "community-based," "community," "epidemiology," "epidemiological," "incidence," "survey," "surveillance," "stroke," "isch(a)emic stroke," "intracerebral," "intraparenchymal," "subarachnoid," and " $h(a)$ emorrhage" were used. Only papers published in English were reviewed. Only papers reporting incidence rates of first-ever stroke in a lifetime in subjects under 45 years of age were included. Moreover, studies were included if the lower age limit was less than 20. Stroke had to be defined according to the WHO definition, that is the occurrence of rapidly developing signs of focal or global disturbance of cerebral function, lasting longer than 24 hours or leading to death, with no apparent cause other than that of vascular origin.

Two of the authors reviewed all published data of selected studies and assessed age and sex distribution of population at risk and of cases of first-ever stroke occurring in those populations.

Repeated reporting of the same studies were excluded, so that each data set was considered only once. Stroke type classification was considered only in those studies where CT, MRI, or autopsy findings were available for at least $80 \%$ of stroke cases. Strokes were classified into four major types: ischemic stroke (if CT or MRI within 30 days of stroke 
TABLE 1: Studies on incidence of stroke in the young.

\begin{tabular}{|c|c|c|c|c|c|}
\hline \multirow{2}{*}{ Study } & \multirow[b]{2}{*}{ Person* year } & \multirow[b]{2}{*}{ Crude rate } & \multicolumn{2}{|c|}{$95 \%$ CI } & \multirow{2}{*}{ Adjusted rate* } \\
\hline & & & LL & UL & \\
\hline Stockholm & $4,712,240$ & 15.56 & 14.43 & 16.68 & 17.25 \\
\hline Benghazi & 158,348 & 39.79 & 29.96 & 49.61 & 48.51 \\
\hline Lund-Orup & 97,283 & 9.25 & 3.21 & 15.30 & 9.28 \\
\hline Denmark & $13,144,499$ & 14.94 & 14.28 & 15.60 & 11.21 \\
\hline Dijon & 75,880 & 26.36 & 14.81 & 37.91 & 31.42 \\
\hline Florence & 531,597 & 8.84 & 6.31 & 11.37 & 8.88 \\
\hline OCSP & 226,936 & 9.64 & 5.60 & 13.68 & 9.74 \\
\hline Russia $^{\dagger}$ & 350,432 & 19.12 & 14.54 & 23.70 & 19.13 \\
\hline Baltimore whites & 388,532 & 13.64 & 9.97 & 17.31 & 14.14 \\
\hline Baltimore blacks & 272,464 & 30.83 & 24.24 & 37.42 & 34.20 \\
\hline Reggio Emilia & 212,646 & 13.64 & 8.67 & 18.60 & 13.95 \\
\hline Aosta 1988 & 67,784 & 13.28 & 4.60 & 21.95 & 13.26 \\
\hline Rochester & $1,297,209$ & 8.63 & 7.03 & 10.23 & 14.21 \\
\hline Malmö $^{\dagger}$ & 127,581 & 11.76 & 5.81 & 17.71 & 10.06 \\
\hline Israel & $2,170,500$ & 5.76 & 4.75 & 6.77 & 6.14 \\
\hline Auckland & 456,667 & 20.15 & 16.03 & 24.26 & 21.02 \\
\hline Perth & 93,086 & 20.41 & 11.23 & 29.59 & 13.83 \\
\hline Warsaw & 230,108 & 16.51 & 11.26 & 21.76 & 13.51 \\
\hline Belluno & 126,513 & 10.28 & 4.69 & 15.86 & 16.70 \\
\hline Innherred $^{\dagger}$ & 73,862 & 12.18 & 4.22 & 20.15 & 12.02 \\
\hline Northern Sweden & 774,608 & 11.36 & 8.99 & 13.73 & 11.17 \\
\hline South London & 327,384 & 10.69 & 7.15 & 14.23 & 11.48 \\
\hline L'Aquila & 874,375 & 10.18 & 8.06 & 12.29 & 10.23 \\
\hline OXVASC & 178,071 & 8.99 & 4.58 & 13.39 & 13.12 \\
\hline Erlangen & 62,453 & 16.01 & 6.09 & 25.94 & 14.58 \\
\hline Northen Manhattan ${ }^{\dagger}$ & 321,739 & 23.00 & 17.76 & 28.24 & 23.03 \\
\hline Aosta $1997^{\dagger}$ & 66,698 & 16.49 & 6.75 & 26.24 & 16.38 \\
\hline Melbourne & 84,888 & 20.03 & 10.51 & 29.55 & 19.25 \\
\hline Brazil & 844,378 & 11.55 & 9.26 & 13.85 & 8.70 \\
\hline
\end{tabular}

CI indicates confidence interval.

* Standardized to the 2000 European population.

${ }^{\dagger}$ Standardized only by sex.

TABLE 2: Estimated incidence rates stratified by age and sex.

\begin{tabular}{lll}
\hline Age class & Males & Females \\
\hline $0-14$ yr & 0.99 & 0.73 \\
$15-24$ yr & 4.20 & 2.95 \\
$25-34$ yr & 10.68 & 7.67 \\
$35-44$ yr & 30.66 & 23.99 \\
\hline
\end{tabular}

showed infarct or no relevant lesion and/or autopsy showed ischemic stroke), primary intracerebral haemorrhage (if shown on CT, MRI, or autopsy), subarachnoid haemorrhage (classified by characteristic findings in CSF analysis and/or autopsy, CT, or cerebral angiography), and undetermined stroke (no CT, MRI, autopsy, cerebral angiography, or [for subarachnoid haemorrhage only] CSF examination was done).
The incidence of first-ever stroke was calculated per 100,000 person-years. Age standardisation was performed with the direct method using the 2000 European population as the reference population [26]. Age-standardised incidence rates were plotted with the corresponding 95\% CI for each study to facilitate comparison. Poisson regression analysis was used to compare incidence rates from different studies. Fitted values were assumed as the best estimates of the true stroke incidence in the young at the various age classes. Sensitivity analysis was performed by excluding those studies that produced a significant deviance change when removed from the model.

\section{Results}

During the review period we identified 29 studies including altogether 3548 patients under 45 years of age with 
Table 3: Proportion of different stroke types in the included studies.

\begin{tabular}{|c|c|c|c|c|c|c|}
\hline \multirow[b]{2}{*}{ Study } & \multicolumn{2}{|c|}{ IS } & \multicolumn{2}{|c|}{ ICH } & \multicolumn{2}{|c|}{ SAH } \\
\hline & $\%$ & $95 \% \mathrm{CI}$ & $\%$ & $95 \% \mathrm{CI}$ & $\%$ & $95 \% \mathrm{CI}$ \\
\hline Stockholm & 21.0 & $18.1-24.0$ & 22.0 & $19.0-25.0$ & 55.4 & $51.8-59.0$ \\
\hline Benghazi & 77.9 & $67.7-88.2$ & 12.6 & $4.4-20.8$ & 9.6 & $2.3-16.8$ \\
\hline Lund-Orup & 67.5 & $48.1-87.0$ & 16.7 & $1.2-32.2$ & 15.8 & $0.6-31.0$ \\
\hline Florence & 38.5 & $24.5-52.4$ & 21.5 & $9.7-33.2$ & 36.2 & $22.5-49.9$ \\
\hline OCSP & 66.7 & $48.9-84.4$ & 3.7 & $0-10.8$ & 29.6 & $12.4-46.9$ \\
\hline Baltimore whites & 77.4 & $66.1-88.6$ & 22.6 & $11.4-33.9$ & - & - \\
\hline Baltimore blacks & 70.2 & $60.5-80.0$ & 29.8 & $20.0-39.5$ & - & - \\
\hline Reggio Emilia & 58.7 & $40.7-76.6$ & 20.5 & $5.8-35.2$ & 20.5 & $5.8-35.2$ \\
\hline Malmö & 53.3 & $28.1-78.6$ & 20.0 & $0-40.2$ & 13.3 & $0-30.5$ \\
\hline Perth & 47.5 & $32.0-63.0$ & 20.0 & $7.6-32.4$ & 32.5 & $18.0-47.0$ \\
\hline Belluno & 30.8 & $05.7-55.9$ & 38.5 & $12.0-64.9$ & 30.8 & $5.7-55.9$ \\
\hline Innherred & 55.6 & $23.1-88.0$ & 33.3 & $2.5-64.1$ & 11.1 & $0-31.6$ \\
\hline L'Aquila & 57.3 & $47.0-67.6$ & 20.2 & $11.9-28.6$ & 22.5 & $13.8-31.1$ \\
\hline OXVASC & 66.7 & $48.9-84.4$ & 3.7 & $0-10.8$ & 29.6 & $12.4-46.9$ \\
\hline Erlangen & 70.0 & $41.6-98.4$ & 10.0 & $0-28.6$ & 20.0 & $0-44.8$ \\
\hline Northen Manhattan & 43.5 & $32.2-54.8$ & 30.4 & $20.0-40.9$ & 26.1 & $16.1-36.1$ \\
\hline
\end{tabular}

$\mathrm{CI}$ indicates confidence interval.

IS indicates ischemic stroke; ICH indicates intracerebral hemorrhage; SAH indicates subarachnoid hemorrhage.

a diagnosis of stroke. Person-year at risk, crude incidence rates, and rates standardized to the 2000 European population are reported in Table 1 . Crude rates ranged from $5.76 / 100,000$ to $39.79 / 100,000$ and standardized rates ranged from $6.14 / 100,000$ to $48.51 / 100,000$. However, after excluding 4 outliers (Benghazi, Dijon, Baltimore-blacks, and Israel, ranges became much tighter (8.63 to $19.12 / 100,000$, for crude rates, and 8.70 to 21.02 , for standardized rates). Figure 1 shows that rates were approximately similar among studies.

Poisson regression analysis revealed a significant heterogeneity among studies $(P<.0001)$. However, after excluding the above mentioned outliers, heterogeneity markedly reduced, although was still statistically significant $(P=.021)$. Fitted values for each age class of both sexes are reported in Table 2 and show rates clearly higher in men than in women.

The distributions of stroke types were reported by half of the papers only, mostly without age and sex stratification (Table 3). The proportion of ischemic stroke ranged between $21.0 \%$ and $77.9 \%$, the proportion of intracerebral hemorrhage ranged between $3.7 \%$ and $38.5 \%$, and the proportion of subarachnoid hemorrhage ranged between $9.6 \%$ and $55.4 \%$.

\section{Discussion}

In subjects under 45 years of age the annual crude incidence rate of first-ever stroke is usually considered low. However, it is usually higher than that of other invalidating neurological disease.

The strength of the present study relies on the inclusion of a large number of studies and of participants. How- ever, studies were rather heterogeneous on the basis of methodology and ethnicity. Higher rates were reported by few studies with less accurate identification of the study population $[2,29,30]$. Rates were higher in USA black people and in developing countries. Racial composition of the study population is an important component of incidence variability since young blacks and hispanics have been shown to have greater stroke incidences than young whites $[3,11]$. Nevertheless, in some developing countries higher rates may reflect life style and inaccurate control of risk factors.

The proportion of ischemic strokes, ranging between $21.0 \%$ and $77.9 \%$, was much lower than that reported for stroke of all ages. This finding probably depended on the occurrence of hemorrhagic strokes due to vascular malformations, and illicit drug use as well as on the lower prevalence of atherosclerosis in young subjects.

Although stroke was a rare event in the young, due to the longer expected survival at this age, young patients accounted for as much as $20 \%$ of the years of potential life lost because of the stroke [31]. Primary prevention is likely to be the principal strategy to fight stroke in the young. In addition to conventional stroke risk factors, young patients have special risk factors inherent to genetic and environmental elements, such as cardiac abnormalities, thrombophylic states, migraine, the use of oral contraceptives and illicit drugs that should be identified and adequately controlled [32]. The high proportion of subarachnoid and intracerebral hemorrages in patients under 45 years reported by some studies, makes mandatory tailored preventive strategies, mainly focused on early detection and treatment of hypertension and possibly including neuroimaging studies for the screening of aneurysms and arteriovenous malformations in subjects at risk. 


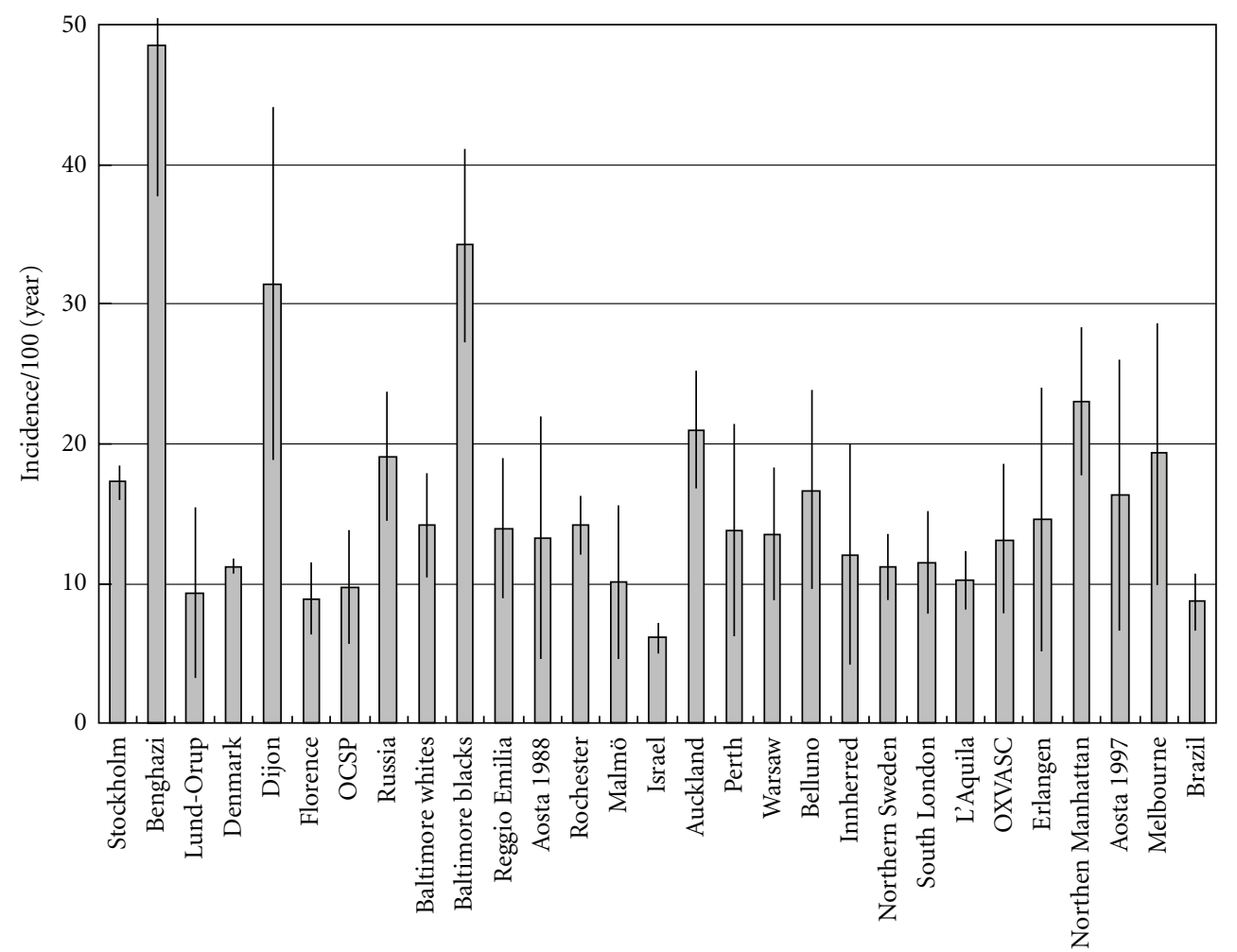

FIGURE 1: Incidence rates of stroke in the young (rates are adjusted for age and sex to the 2000 European population).

\section{Conclusion}

Studies on incidence of stroke in the young provide comparable rates showing that stroke in those subjects is not such a rare condition and requires tailored prevention programs.

\section{References}

[1] P. Nencini, D. Inzitari, M. C. Baruffi et al., "Incidence of stroke in young adults in Florence, Italy," Stroke, vol. 19, no. 8, pp. 977-981, 1988.

[2] K. Radhakrishnan, P. P. Ashok, R. Sridharan, and M. E. Mousa, "Stroke in the young: incidence and pattern in Benghazi, Libya," Acta Neurologica Scandinavica, vol. 73, no. 4, pp. 434438,1986

[3] S. J. Kittner, R. J. McCarter, R. W. Sherwin et al., "Black-white differences in stroke risk among young adults," Stroke, vol. 24, supplement 1, pp. I13-I15, 1993.

[4] H. Ellekjær, J. Holmen, B. Indredavik, and A. Terent, "Epidemiology of stroke in Innherred, Norway, 1994 to 1996: incidence and 30-day case-fatality rate," Stroke, vol. 28, no. 11, pp. 2180-2184, 1997.

[5] D. Guidetti, M. Baratti, R. Zucco et al., "Incidence of stroke in young adults in the Reggio Emilia area, Northern Italy," Neuroepidemiology, vol. 12, no. 2, pp. 82-87, 1993.

[6] J. Bamford, P. Sandercock, M. Dennis, J. Burn, and C. Warlow, "A prospective study of acute cerebrovascular disease in the community: the Oxfordshire Community Stroke Project1981-86. 2. Incidence, case fatality rates and overall outcome at one year of cerebral infarction, primary intracerebral and subarachnoid haemorrhage," Journal of Neurology Neurosurgery and Psychiatry, vol. 53, no. 1, pp. 16-22, 1990.
[7] P. Jerntorp and G. Berglund, "Stroke registry in Malmö, Sweden," Stroke, vol. 23, no. 3, pp. 357-361, 1992.

[8] C. S. Anderson, K. D. Jamrozik, P. W. Burvill, T. M. H. Chakera, G. A. Johnson, and E. G. Stewart-Wynne, "Ascertaining the true incidence of stroke: experience from the Perth Community Stroke Study, 1989-1990," Medical Journal of Australia, vol. 158, no. 2, pp. 80-84, 1993.

[9] A. Czlonkowska, D. Ryglewicz, T. Weissbein, M. BaranskaGieruszczak, and D. B. Hier, "A prospective community-based study of stroke in Warsaw, Poland," Stroke, vol. 25, no. 3, pp. 547-551, 1994.

[10] G. Lauria, M. Gentile, G. Fassetta et al., "Incidence and prognosis of stroke in the Belluno Province, Italy: first- year results of a community-based study," Stroke, vol. 26, no. 10, pp. 1787-1793, 1995.

[11] B. S. Jacobs, B. Boden-Albala, I. F. Lin, and R. L. Sacco, "Stroke in the young in the Northern Manhattan stroke study," Stroke, vol. 33, no. 12, pp. 2789-2793, 2002.

[12] K. L. Mettinger, C. E. Soderstrom, and E. Allander, "Epidemiology of acute cerebrovascular disease before the age of 55 in the Stockholm County 1973-77: I. Incidence and mortality rates," Stroke, vol. 15, no. 5, pp. 795-800, 1984.

[13] P. M. Rothwell, A. J. Coull, M. F. Giles et al., "Change in stroke incidence, mortality, case-fatality, severity, and risk factors in Oxfordshire, UK from 1981 to 2004 (Oxford Vascular Study)," Lancet, vol. 363, no. 9425, pp. 1925-1933, 2004.

[14] L. Epstein, S. Rishpon, E. Bental et al., "Incidence, mortality, and case-fatality rate of stroke in northern Israel," Stroke, vol. 20, no. 6, pp. 725-729, 1989.

[15] O. Lidegaard, M. Soe, and M. V. N. Andersen, "Cerebral thromboembolism among young women and men in Denmark 1977-1982," Stroke, vol. 17, no. 4, pp. 670-675, 1986. 
[16] N. L. Cabral, A. R. R. Gonçalves, A. L. Longo et al., "Trends in stroke incidence, mortality and case fatality rates in Joinville, Brazil: 1995-2006," Journal of Neurology, Neurosurgery and Psychiatry, vol. 80, no. 7, pp. 749-754, 2009.

[17] P. Harmsen, L. Wilhelmsen, and A. Jacobsson, "Stroke incidence and mortality rates 1987 to 2006 related to secular trends of cardiovascular risk factors in Gothenburg, Sweden," Stroke, vol. 40, no. 8, pp. 2691-2697, 2009.

[18] J. A. Stewart, R. Dundas, R. S. Howard, A. G. Rudd, and C. D. A. Wolfe, "Ethnic differences in incidence of stroke: prospective study with stroke register," British Medical Journal, vol. 318, no. 7189, pp. 967-971, 1999.

[19] B. Norrving and P. Lowenhielm, "Epidemiology of stroke in Lund-Orup, Sweden, 1983-85. Incidence of first stroke and age-related changes in subtypes," Acta Neurologica Scandinavica, vol. 78, no. 5, pp. 408-413, 1988.

[20] G. D’Alessandro, M. Di Giovanni, L. Roveyaz et al., "Incidence and prognosis of stroke in the Valle d'Aosta, Italy: first-year results of a community-based study," Stroke, vol. 23, no. 12, pp. 1712-1715, 1992.

[21] R. D. Brown, J. P. Whisnant, J. D. Sicks, W. M. O’Fallon, and D. O. Wiebers, "Stroke incidence, prevalence, and survival: secular trends in Rochester, Minnesota, through 1989," Stroke, vol. 27, no. 3, pp. 373-380, 1996.

[22] G. D’Alessandro, E. Bottacchi, M. Di Giovanni et al., “Temporal trends of stroke in Valle d'Aosta, Italy. Incidence and 30-day fatality rates," Neurological Sciences, vol. 21, no. 1, pp. 13-18, 2000.

[23] P. L. Kolominsky-Rabas, C. Sarti, P. U. Heuschmann et al., "A prospective community-based study of stroke in Germanythe Erlangen Stroke Project (ESPro): incidence and case fatality at 1, 3, and 12 months," Stroke, vol. 29, no. 12, pp. 2501-2506, 1998.

[24] D. Christie, "Stroke in Melbourne, Australia: an epidemiological study," Stroke, vol. 12, no. 4, pp. 467-469, 1981.

[25] V. L. Feigin, D. O. Wiebers, Y. P. Nikitin, W. M. O'Fallon, and J. P. Whisnant, "Stroke epidemiology in Novosibirsk, Russia: a population-based study," Mayo Clinic Proceedings, vol. 70, no. 9, pp. 847-852, 1995.

[26] C. Marini, R. Totaro, F. De Santis, I. Ciancarelli, M. Baldassarre, and A. Carolei, "Stroke in young adults in the community-based L'Aquila registry: incidence and prognosis," Stroke, vol. 32, no. 1, pp. 52-56, 2001.

[27] A. Carolei, C. Marini, M. Di Napoli et al., "High stroke incidence in the prospective community-based L'Aquila registry (1994-1998): first year's results," Stroke, vol. 28, no. 12, pp. 2500-2506, 1997.

[28] N. Rozenthul-Sorokin, R. Ronen, A. Tamir, H. Geva, and R. Eldar, "Stroke in the young in Israel: incidence and outcomes," Stroke, vol. 27, no. 5, pp. 838-841, 1996.

[29] M. Giroud, P. Beuriat, P. Vion, P. H. D’Athis, L. Duserre, and R. Dumas, "Stroke in a French prospective population study," Neuroepidemiology, vol. 8, no. 2, pp. 97-104, 1989.

[30] R. Bonita, J. B. Broad, and R. Beaglehole, "Changes in stroke incidence and case-fatality in Auckland, New Zealand, 198191," Lancet, vol. 342, no. 8885, pp. 1470-1473, 1993.

[31] C. Marini, R. Totaro, and A. Carolei, "Long-term prognosis of cerebral ischemia in young adults," Stroke, vol. 30, no. 11, pp. 2320-2325, 1999.

[32] H. Naess and U. Waje-Andreassen, "Review of long-term mortality and vascular morbidity amongst young adults with cerebral infarction," European Journal of Neurology, vol. 17, no. 1, pp. 17-22, 2010. 


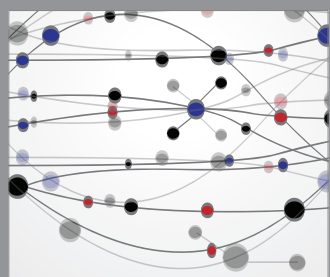

The Scientific World Journal
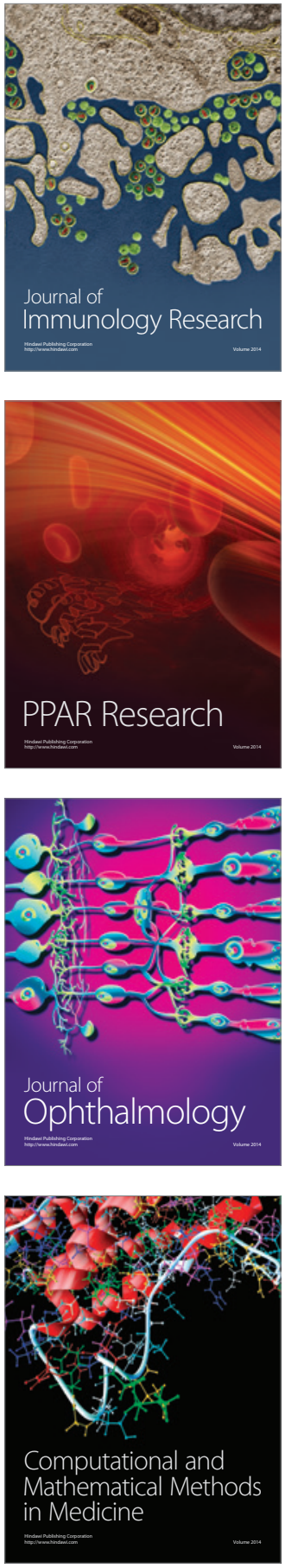

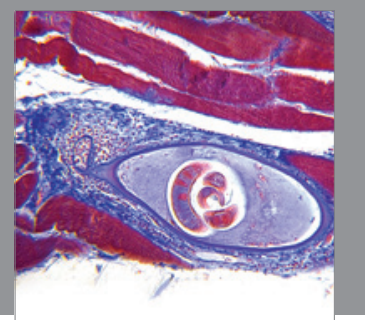

Gastroenterology

Research and Practice
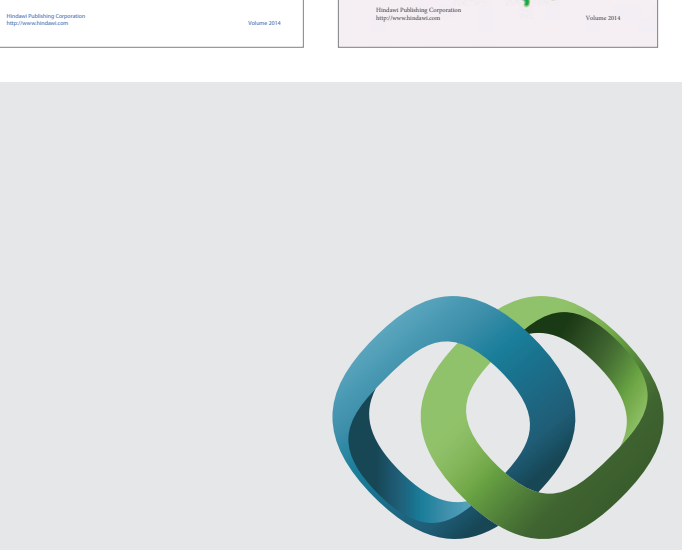

\section{Hindawi}

Submit your manuscripts at

http://www.hindawi.com
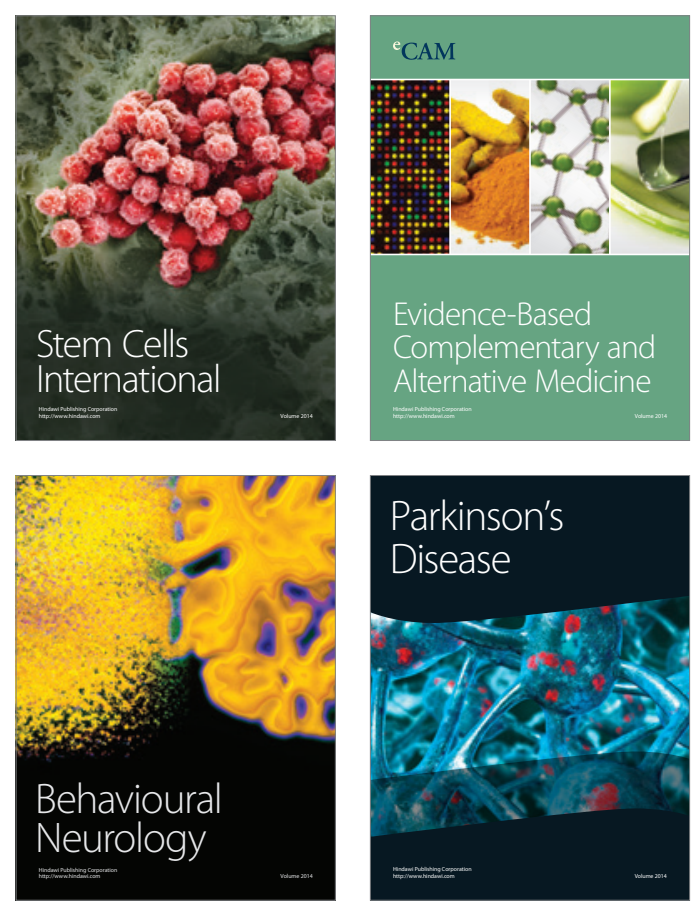

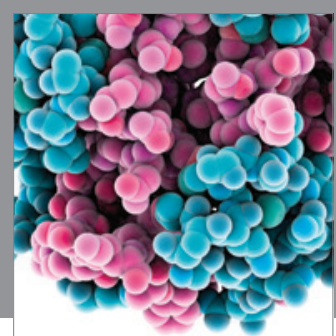

Journal of
Diabetes Research

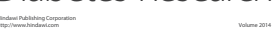

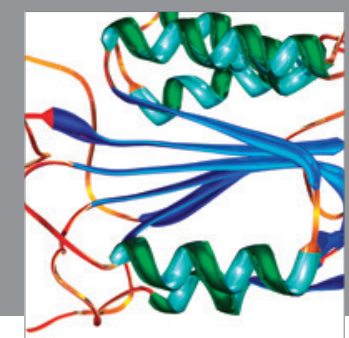

Disease Markers
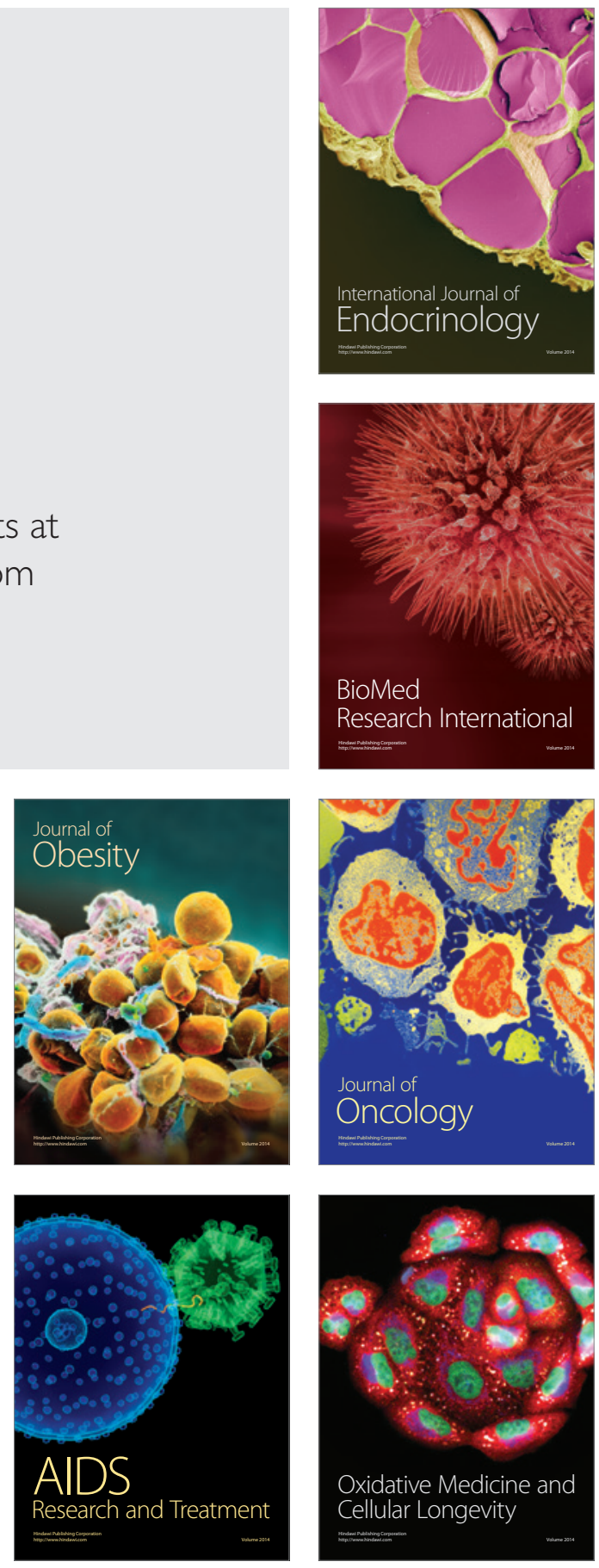